\title{
COVID-19 vaccination induced axillary nodal uptake on [18F] FDG PET/CT
}

\author{
Ayah Adel Nawwar $^{1,2}$ (D) Julie Searle ${ }^{1,3} \cdot \operatorname{Ian}$ Hagan $^{1,3} \cdot$ lain Douglas Lyburn 1,3,4 \\ Received: 12 February 2021 / Accepted: 18 February 2021 / Published online: 26 February 2021 \\ (C) The Author(s), under exclusive licence to Springer-Verlag GmbH, DE part of Springer Nature 2021
}

Worldwide mass COVID-19 vaccination is being deployed. A 76-year-old female with oligosecretory myeloma disease underwent follow-up [18F]FDG PET/CT, which demonstrated no definite [18F]FDG avid disease; however, an avid left axillary node and superficial uptake in the left upper arm were noted. a

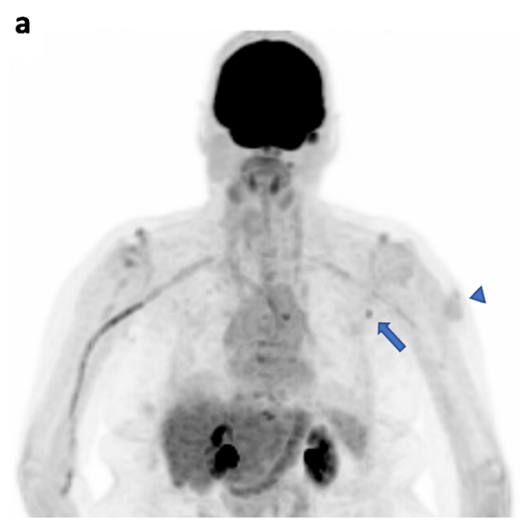

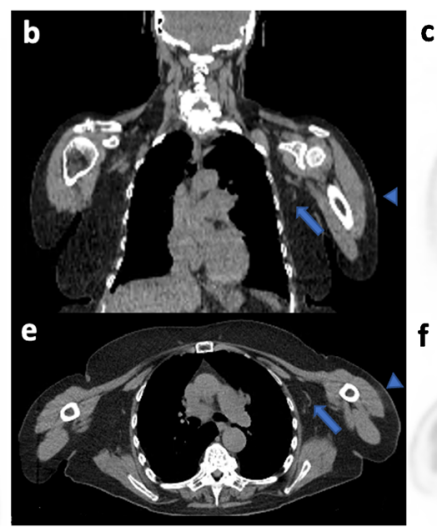
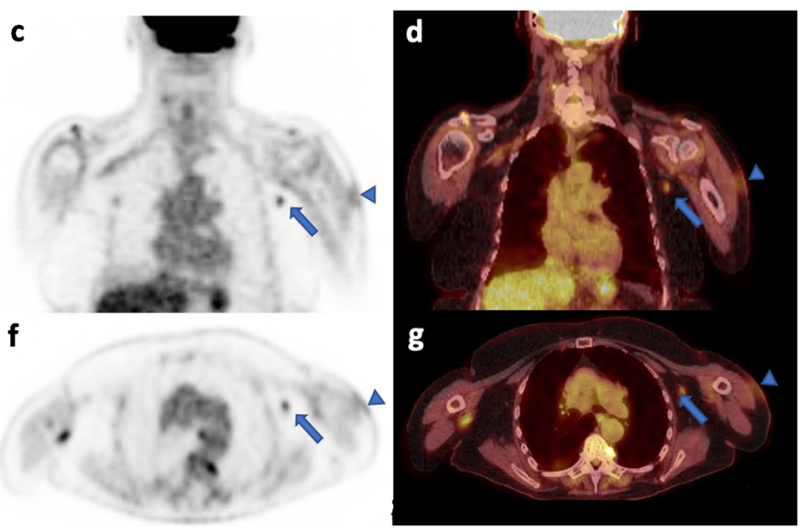

This article is part of the Topical Collection on Image of the month.

Ayah Adel Nawwar

ayah.nawwwar@doctors.net.uk

1 Cobalt Medical Charity, Linton House, Thirlestaine Rd, Cheltenham GL53 7AS, UK

2 Clinical Oncology and Nuclear Medicine Department, Cairo University, Cairo, Egypt

3 Gloucestershire Hospitals NHS Foundation Trust, Cheltenham GL53 7AN, UK

4 Cranfield University, College Rd, Cranfield, Wharley End, Bedford MK43 0AL, UK
[18F]FDG PET/CT maximal intensity projection (MIP) (a) demonstrate focal uptake in the left axilla (arrow) and ill-defined subcutaneous uptake in the left arm (arrowhead). Tracer injection was via the right antecubital fossa. Coronal and axial CT, [18F]FDG PET, and fused [18F]FDG PET/CT of the chest $(\mathrm{b}-\mathrm{g})$ demonstrate lowgrade uptake within the subcutaneous soft tissues superficial to the left deltoid (arrowheads) and within a level I left axillary node (arrows).

The patient had been administered the OxfordAstraZeneca COVID-19 vaccination in the left upper arm 2 weeks earlier. Subcutaneous uptake adjacent to the deltoid 
is in keeping with the recent injection. On reviewing the CT component and correlating with the clinical history, the nodal uptake was concluded to be reactive, related to the recent vaccination. A similar case was described with PfizerBioNTech COVID-19 vaccination in January 2021 [1].

This case highlights a new [18F]FDG PET/CT pitfall associated with the current COVID-19 pandemic that reporters should be made aware of, to avoid potential disease upstaging and overtreatment.

\section{Declarations}

Conflict of interest The authors declare no competing interests.

\section{Reference}

1. Eifer M, Eshet Y. Imaging of COVID-19 vaccination at FDG PET/ CT. Radiol Radiol Soc N Am. 2021;210030.

Publisher's note Springer Nature remains neutral with regard to jurisdictional claims in published maps and institutional affiliations. 